\title{
Ensinar Padrões de Herança Mendelianos Utilizando Caracteres Humanos Percepção dos Professores
}

\author{
Cléia Rosani Baiotto ${ }^{1}$ \\ Élgion Lucio da Silva Loreto
}

\begin{abstract}
Resumo
Inúmeras dificuldades estão atreladas ao ensino dos padrões de herança. Destacam-se a extensa lista de conceitos, os cálculos associados às perspectivas de segregação desses padrões de herança e a falta de contextualização relacionada a essa temática. Para resolver o problema da contextualização, os professores recorrem à utilização de caracteres humanos como exemplos de padrões de herança monogênicos. Uma entrevista com $94 \%$ dos professores de Biologia $(n=17)$ da rede básica de ensino do município de Cruz Alta (RS, Brasil), buscou verificar como eles avaliam essa situação. Percebe-se um consenso entre os entrevistados com relação a essas dificuldades, pois destacam a necessidade de empregam caracteres humanos, considerando que estes despertam a curiosidade natural, utilizam os conhecimentos prévios e o cotidiano dos alunos, resgatam questões culturais atreladas à transmissão de características e tornam a aprendizagem mais efetiva. Descrevem que o melhor aproveitamento dos alunos está associado à curiosidade e ao interesse despertado pelo tema. Embora o uso de caracteres humanos herdados tenha um efeito positivo significativo no ensino de Genética, acarreta dificuldades, como a possibilidade de gerar constrangimentos associados a questões de familiaridade e grau de parentesco, descrédito na informação científica em razão da inconformidade familiar e exige do professor uma constante atualização.
\end{abstract}

Palavras-chave: Ensino de genética. Mendel. Caracteres humanos. Professores.

1 Doutora em Educação em Ciências - Química da Vida e Saúde (UFSM). Mestre em Genética e Biologia Molecular (UFRGS). Docente do Centro de Ciências da Saúde e Agrárias da Universidade de Cruz Alta, Cruz Alta, RS. cbaiotto@unicruz.edu.br

2 Doutor em Genética e Biologia Molecular, professor associado do Departamento de Bioquímica e Biologia, Universidade Federal de Santa Maria, Santa Maria, RS. Orcid: < http://orcid.org/00000002-7586-8168>.elgionl@gmail.com 
TEACHING MENDELIAN PATTERNS OF INHERITANCE USING HUMAN CHARACTERS - TEACHER PERCEPTION

\begin{abstract}
Numerous difficulties are linked to the teaching patterns of heredity. We highlight the extensive list of concepts, the calculations associated with the perspectives of segregation of these inheritance patterns, and the lack of contextualization related to this theme. To solve the problem of contextualization teachers use human characters as examples of monogenic inheritance patterns. An interview with $94 \%$ of the Biology teachers $(n=17)$ of the basic education network of the city of Cruz Alta (RS, Brazil), sought to verify how they evaluate this situation. It is perceived consensus among respondents with regard to these difficulties highlight the need to use human characters, whereas these awaken the natural curiosity, using prior knowledge and the daily lives of students, rescuing cultural issues linked to transmission characteristics and make learning. They describe that the best use of students is associated with curiosity and interest aroused by the theme. Although the use of inherited human characters has a significant positive effect on the teaching of genetics, it entails difficulties such as the possibility of generating constraints associated with familiarity and degree of kinship, discrediting of scientific information due to family nonconformity, and requiring the teacher to constantly update.
\end{abstract}

Keywords: Genetic Education. Mendel. Human Characters. Teachers.

Recebido em: 31/8/2017

Aceito em: 4/12/2017 
Apesar de presente na mídia e inserida nas falas corriqueiras da população, a Genética tem sido apontada como um dos componentes curriculares no qual se concentram as maiores dificuldades no ensino de Biologia. Diferentes autores têm relatado as dificuldades observadas com ênfase ao campo da Genética. Entre elas, destacam-se: a falta de contextualização e excesso de memorização (MOURA et al., 2013; BEZERRA; GOULART, 2014); concepções errôneas, sob o ponto de vista científico, de alunos de Ensino Médio (PAIVA; MARTINS, 2005); distanciamento entre a produção do conhecimento e a atualização dos materiais didáticos (LORETO; SEPEL, 2003); nível de conhecimento em estudantes de Ensino Médio (GIACÓIA, 2006); dificuldades conceituais (TSUI; TREAGUS, 2007; INFANTE-MALACHIAS et al., 2010; SMITH; KNIGTH, 2012) e dificuldades de aprendizagem (CIMER, 2012).

Knippels, Waarlo e Boersma (2005), ao identificarem as dificuldades conceituais relativas ao ensino de Genética, organizaram-nas em dez categorias. Duas se destacam no ensino de Genética: a complexidade e o nível de abstração necessários para o entendimento da disciplina. Não usar contextos de vida cotidiana ou problemas que têm relevância pessoal ou social amplia, na percepção dos autores, a abstração, e determina uma perda de motivação entre os estudantes. Sugerem, desse modo, iniciar o conteúdo com o que os alunos estão familiarizados (o indivíduo), observando semelhanças e diferenças entre os traços da sua família.

Os elevados níveis de abstração exigidos para a construção do conhecimento em Genética e a reduzida utilização de recursos didáticos, têm gerado desinteresse, dificultando a contextualização e a compreensão dos inúmeros conceitos necessários ao entendimento dos padrões de herança em Genética (CASTELÃO; AMABIS, 2008).

As dificuldades relacionadas à compreensão no ensino de Genética podem, no entanto, ser minimizadas se houver possibilidade de aumentar o interesse dos alunos em relação ao tema desenvolvido (MALAFAIA; BÁRBARA; RODRIGUES, 2010), pelo uso de modelos didáticos que favoreçam a 
concepção da ciência como uma construção sociocultural e histórico-social, ao mesmo tempo em que auxiliam na compreensão dos conceitos fundamentais da disciplina (SCHEID; FERRARI, 2006).

Kato e Kawasaki (2011) complementam que a fragmentação dos conteúdos do seu contexto de produção exige trazer a vivência dos alunos para o contexto de aprendizagem a partir de diferentes momentos do seu cotidiano, identificando situações e fenômenos vivenciados, e possibilitando, assim, uma melhor contextualização dos conceitos de modo a tornar o ensino mais efetivo.

A contextualização pedagógica do conteúdo científico pode ser visualizada por intermédio da concretização dos conteúdos curriculares, de modo a torná-los socialmente mais relevantes (SANTOS, 2007). Kato e Kawasaki (2011), ao avaliarem as diferentes concepções de contextualização do ensino, reuniram elas em três grupos: a) relacionadas ao cotidiano do aluno; b) relacionadas à(s) disciplina(s) escolar(res); c) relacionadas aos contextos histórico, social e cultural.

$\mathrm{O}$ uso de caracteres humanos herdados favorece o processo de aprendizagem, pois utiliza questões pessoais do aprendiz e parte de um cenário de informações a respeito de herança presente no senso comum, atendendo às categorias supradescritas. A existência de conceitos prévios e as características observáveis em si próprios como forma de contextualizar o ensino dos padrões de herança na Genética, possibilitam a construção do conhecimento e permitem que a aprendizagem se torne significativa, como exposto por Novak (2011).

A necessidade de contextualização, apontada como imprescindível e necessária nos Parâmetros Curriculares Nacionais do Ensino Médio para o desenvolvimento das competências e habilidades (BRASIL, 1999), vem progressivamente reforçando a discussão e ampliando a utilização de caracteres humanos hereditários no ensino de "genética mendeliana", valorizando as questões pessoais, sociais e culturais. Nesse sentido, traços hereditários humanos vêm se destacando nas versões mais atuais dos livros didáticos e na contextualização do ensino de Genética, em virtude de que aproximam os leitores do seu dia a dia em relação a outros caracteres de animais e vegetais, distantes e pouco significativos para o aluno do Ensino Médio (BAIOTTO; SEPEL; LORETO, 2016). 
Ensinar padrões de herança com a utilização de exemplos de caracteres humanos atrai e mantém o foco dos alunos. Simplificações, desvios e erros conceituais implícitos nos livros didáticos, no entanto, como referências para o Ensino Médio (PNLD), podem ampliar as dificuldades nesse campo da Genética (BAIOTTO; SEPEL; LORETO, 2016).

Além disso, concepções alternativas têm se revelado importantes dificuldades no ensino de Genética. Evidências importantes de que conceitos e ideias preexistentes geram dificuldades no entendimento de conteúdos considerados complexos, relativos à hereditariedade, foram estudo envolvendo alunos do Ensino Médio por Paiva e Martins (2005) e Cirne e Costa (2015). Estudos de Altunoolu e Seker (2015) com acadêmicos de cursos de Licenciatura, demonstram que as concepções alternativas estão presentes nesse grupo e, provavelmente, acompanham o professor em sua trajetória profissional. Os autores destacam que os professores, que deveriam ter a literacia científica para trabalhar as questões relativas aos novos conceitos em Genética, são, na verdade, um dos motivos de equívocos dos estudantes.

Da mesma forma, Infante-Malachias et al. (2010), ao avaliarem estudantes ingressantes dos cursos de Graduação da área da saúde com relação ao grau de compreensão de Genética Básica, relatam que os acadêmicos participantes da pesquisa não foram capazes de responder $30 \%$ das questões e, quando o fizeram, demonstraram conhecimento distorcido acerca da Genética, dos seus conceitos e, principalmente, das interações entre eles.

Cabe salientar que a atuação do professor na sala de aula está diretamente relacionada às concepções que possui a respeito do processo de ensino-aprendizagem, de ciência, de educação, bem como das concepções pertinentes a sua área de atuação (PIMENTA; GONÇALVES, 1992). Como agentes transformadores no ensino, essas concepções influenciam na seleção de conteúdos, na contextualização ou descontextualização dada a eles e na relação aluno-conteúdo-professor.

Diante desse quadro, entendeu-se como prioridade conhecer as concepções dos professores a respeito da utilização dos caracteres humanos como forma de contextualização no ensino dos padrões de herança. Problemas de 
transposição didática e dependência do livro para o planejamento, execução e retomadas das atividades, também foram objetos de questionamentos e reflexões importantes na construção deste relato.

\section{Material e Métodos}

Os sujeitos desta pesquisa foram os professores de Biologia da Rede Básica de Ensino, pertencentes a $9^{\mathrm{a}}$ Coordenadoria Regional de Educação (CRE) do município de Cruz Alta/RS. Foram incluídos nesta amostra todos os professores deste componente curricular das sete escolas públicas que oferecem o Ensino Médio. Dos professores contatados por meio da CRE e das direções das escolas, 94\% $(\mathrm{n}=17)$ consentiram em participar da pesquisa.

O instrumento utilizado para a coleta dos dados foi um questionário semiestruturado com perguntas abertas e fechadas aplicadas sob a forma de entrevistas individuais, que permitem identificar percepções que os professores possuem em relação ao uso de caracteres humanos no ensino de Genética e outros aspectos pertinentes à proposta (livros, modo de utilização, dificuldades no ensino de Genética, entre outros). A entrevista permite uma comunicação mais próxima com o entrevistado, facilitando a comunicação (RICHARDSON, 1999) e permitindo explorar pontos de interesse ao longo de seu curso (GIL, 2002).

Os professores convidados a participar da coleta de dados foram previamente informados dos seus objetivos e, após a leitura, assinaram o Termo de Consentimento Livre e Esclarecido (TCLE) do projeto, com registro no Certificado de Apresentação para Apreciação Ética (CAAE) sob o número 20573613.0.0000.5322.

O estudo tem uma abordagem qualitativa do tipo descritiva e exploratória. Gaskell (2002) afirma que a pesquisa qualitativa fornece dados para a compreensão detalhada das crenças, das atitudes, dos valores e da motivação em relação ao comportamento dos indivíduos em contextos sociais específicos. Bardin (2011) complementa que esta abordagem permite inferir conhecimentos relativos às condições de produção/recepção dessas mensagens. 
As entrevistas foram transcritas na sua totalidade, posteriormente reunidas em blocos por temas (categorias) e depois quantificadas. De acordo com Bardin (2011), a categorização permite reunir um maior número de informações à custa de uma esquematização, correlacionando classes de acontecimentos para ordená-los. Questões mais específicas voltadas à utilização dos caracteres humanos no ensino de Genética, com categorias predeterminadas, possibilitaram conhecer o uso dos caracteres humanos no ensino de Genética, suas dificuldades e o modo como utilizam esses caracteres na contextualização de herança monogênica.

Questões gerais com relação ao tempo de atuação, local de formação e experiência na área da Genética, também foram contempladas no instrumento de avaliação, a fim de estabelecer o perfil dos profissionais que atuam no Ensino Médio, mais especificamente no ensino de Genética.

\section{Resultados e Discussão}

A heterogeneidade característica dos padrões de herança humanos pode ser observada entre os entrevistados, principalmente no que se refere à experiência no ensino e tempo de atuação na área. Destacou-se a experiência no ensino de Biologia, que oscila de 1 a 28 anos de atividade, com uma média de 9,67 ( $\pm 7,7)$, posto que 46,5\% destes têm menos de cinco anos no ensino. Com relação à atuação deles no ensino de Genética, a proporção não é muito diferente: a média de tempo de experiência na área corresponde a 5,8 $( \pm 5,2)$, com $66,66 \%$ de professores com menos de cinco anos de experiência.

A inclusão das escolas de Ensino Médio a partir de 2004 no Programa Nacional do Livro Didático para o Ensino Médio (PNLEM) facilitou o acesso do professor aos livros disponibilizados desde 2006 às escolas (BRASIL, 2008; EL-HANI; ROQUE; ROCHA, 2011). Nesse quesito, quando questionados com relação à utilização do livro didático, cabe destacar que todos os professores entrevistados usam os livros que chegam à escola pelo Programa.

Quando questionados sobre o modo como utilizam o livro didático, categorias preestabelecidas definiram os grupos de respostas (texto diário, referência, complementação ou outra), constatando-se que são unânimes em responder que 
empregam como referência diária em seus planejamentos e desenvolvimento das aulas. Ainda, 74\% deles descreveram a utilização de forma complementar, ou seja, aproveitam os tópicos extras, como leituras, curiosidades e demais sugestões no seu planejamento diário; $27 \%$ dos professores ainda mencionam especificamente a resolução dos exercícios sugeridos pelo autor.

Com relação à adoção como livro-texto, apenas $20 \%$ deles, embora utilizem o livro em seu planejamento, não o citam como livro-texto ou de referência, mas afirmam fazer as atividades propostas e os exercícios como complementação da aula (Figura 1). Salienta-se que o fato de as escolas receberem a cada três anos novos exemplares permite que os professores utilizem outras coleções como forma de pesquisa, exercícios e demais atividades complementares. Desse modo, percebe-se que o livro didático ocupa um lugar de destaque no aprendizado de Genética.

Figura 1 - Utilização do livro didático pelos professores no ensino de Biologia

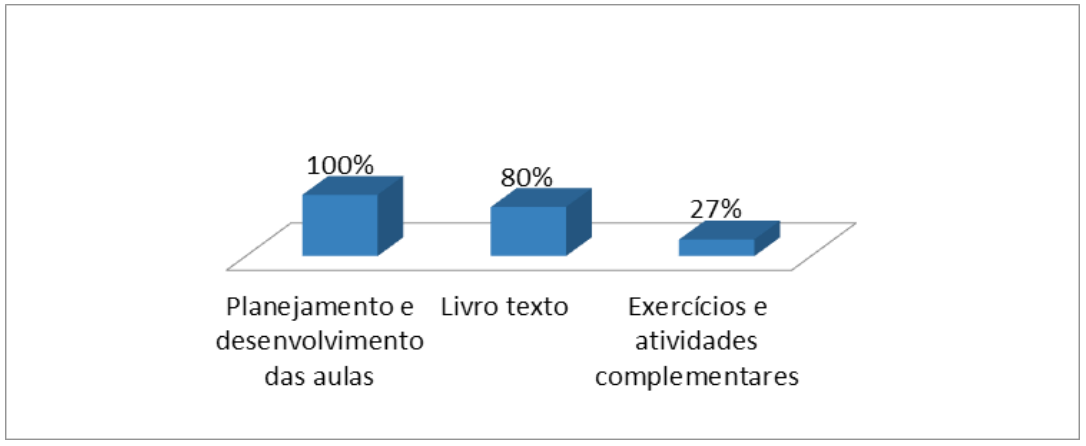

Fonte: Os autores.

Maia e Vilani (2016) afirmam que quanto menor é a formação específica do professor na área maior é a sua dependência do livro didático, pois, entre outros aspectos, essa ferramenta proporciona segurança e é um facilitador para a atuação didática, especialmente para aqueles que ensinam em turnos e instituições diferentes. Inúmeras outras discussões acerca dos livros didáticos em relação a conceitos ou temas específicos de genética refletem a importância assumida pelo livro no ensino, como suporte no planejamento, na organização 
e execução das aulas (GARCIA; BIZZO, 2010; EL-HANI; ROQUE; ROCHA, 2011; FRANZOLIN; TOLENTINO-NETO; BIZZO, 2014; FRANZOLIN; BIZZO, 2015).

O grau de confiabilidade no livro didático utilizado (nem sempre o escolhido no processo seletivo do PNLD) é outro fator importante. Destacam-se quatro grupos de respostas entre os professores entrevistados: 53,3\% confiam plenamente em todas as informações apresentadas nos livros; $26,6 \%$ descrevem esse grau de confiança como "quase sempre", ou seja, questionamentos de aluno ou tópico muito discrepante leva a buscar informações a respeito do apontamento do livro; $13,5 \%$ indicam que nem sempre confiam nas informações; e um professor descreve que não confia mais em decorrência de experiências pessoais no ensino relativas a questionamentos inusitados ou fora do comum por parte dos alunos (Figura 2).

Quando indagados se já tiveram desconfiança no texto dos livros, as respostas se contradizem um pouco em relação à anterior, mostrando que $33,4 \%$ nunca tiveram alguma dúvida quanto às informações descritas nos livros didáticos; $20 \%$ relatam ter dúvida e $46,6 \%$ descrevem que, sim, já tiveram desconfiança (Figura 3).

Figura 2 - Nível de confiabilidade no livro didático

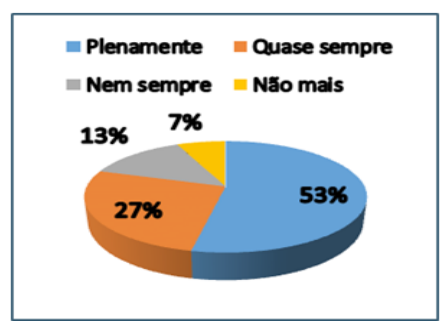

Figura 3 - Nível de desconfiança em relação ao livro didático

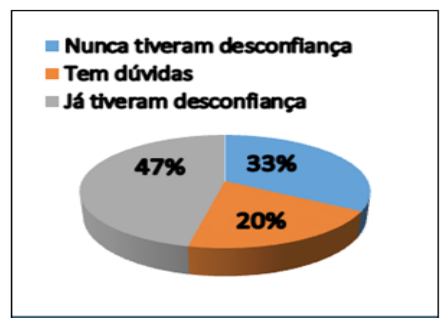

Fonte: Os autores.

Sempre que precisaram solucionar dúvidas pessoais ou questionamentos de alunos com relação ao texto do livro didático, $74 \%$ dos professores resolvem com a ajuda de outros livros didáticos da área, $60 \%$ afirmam utilizar a Internet como fonte de pesquisa e $6 \%$ ainda usam informações do colega para tirar as 
dúvidas (Figura 4). Quando se fragmentam os dados relativos à busca de informações na Internet, percebe-se que poucos $(6 \%)$ dão ênfase à necessidade de buscar essas informações em artigos, e $6 \%$ citam sites ligados ao ensino, como Sociobiologia e Infoescola.

Duas preocupações emergem do questionamento supra. A primeira é reforçada pela grande dependência do livro didático, tendo em vista o longo delay entre a produção do conhecimento científico e as tecnologias associadas e a transposição didática necessária para a produção do livro. A segunda é atrelada à transposição desse saber de modo a torná-lo mais compreensível, utilizando, para tanto, analogias, desvios conceituais e excesso de simplificações que ampliam esse distanciamento e podem se transformar em obstáculos epistemológicos, uma vez que são assumidos pelos professores como verdades científicas (FRANZOLIN; BIZZO, 2015).

Com relação à transposição, é necessário considerar que o conhecimento científico, identificado como "saber sábio" (objeto do saber), ao ser definido como um conteúdo escolarizável passa por um processo de transposição, tendo sua linguagem e símbolos adaptados de acordo com o público-alvo, transformando-se em saber a ser ensinado, e então passa a estar presente nos currículos, livros e materiais didáticos, além de sites na Internet. Esse saber a ser ensinado, submetido a uma nova transformação pelo professor, sofre uma adequação de conteúdo de acordo com sua sala de aula, utilizando analogias, simplificações e contextualizações e, então, é transposto em saber ensinado a partir de concepções pessoais (CHEVALLARD, 1997; CARVALHO, 2010).

Cabe destacar as dificuldades pertinentes à busca de informações mais atualizadas e, ao mesmo tempo, cientificamente corretas. Toledo e Ferreira (2015) fazem uma abordagem das divergências encontradas na transposição didática em sites de divulgação científica, demonstrando muitas inconsistências, principalmente na transferência da imagem concreta para a abstrata. Falta de tempo, excesso de atividades ou despreparo do professor com relação à língua inglesa para acessar informações que permitam sanar dúvidas particulares ou da classe em que trabalha, ampliam essas divergências. 
O uso de caracteres humanos como forma de contextualizar os padrões de herança mendelianos está presente na maioria dos livros didáticos disponíveis no PNLDEM/2012 (87,5\%), e é destacado por todos os professores como prioridade no ensino de Genética (BAIOTTO; SEPEL; LORETO, 2016). É descrito pela totalidade como o modo mais eficiente de aproximar o ensino do cotidiano dos alunos, de modo que desperta a curiosidade e o interesse deles, favorecendo a aprendizagem (Figura 5).

Figura 4 - Busca de informações Figura 5 - Utilização de caracteres em caso de dúvida humanos na contextualização de herança monogênica
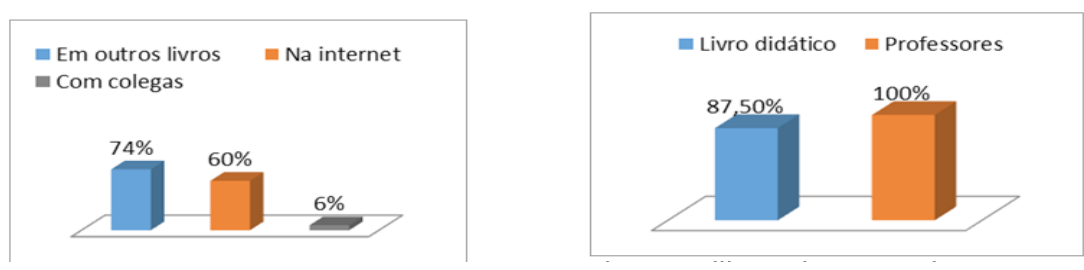

Fonte: Os autores.

Quando se fragmentam esses dados, com relação à utilização de caracteres humanos herdados, identifica-se que $60 \%$ dos professores apontam a facilidade de entendimento e compreensão; $80 \%$ destacam a proximidade do tema atrelado à contextualização do ensino; $20 \%$ reforçam que os caracteres humanos, por fazerem parte do dia a dia dos alunos, favorecem a curiosidade e o interesse, gerando uma série de questionamentos; e, da mesma forma, $20 \%$ ainda destacam o fato de que todos esses enfoques promovem uma melhor e mais significativa aprendizagem (Figura 6).

A utilização de exemplos reais, concretos e próximos do aluno favorece o aprendizado, garante a contextualização, determina um maior interesse e desperta a curiosidade, o que, segundo a totalidade dos professores entrevistados, promove um melhor entendimento dos temas desenvolvidos em genética. Considerar os conhecimentos prévios e o cotidiano dos alunos com o uso de caracteres humanos herdados é visto como elemento importante na contextualização do ensino por Lima et al. (2000) e por Kato e Kawasaki (2011). Esses autores sugerem a aproximação do contexto de vivência dos alunos para o 
contexto de aprendizagem, identificando situações e fenômenos vivenciados com os diferentes contextos de sua produção científica, educacional e social. Silva e Marcondes (2010) afirmam que essa contextualização social, político, econômico e ambiental se constitui em um princípio norteador para uma aprendizagem mais efetiva dos conceitos científicos.

Figura 6 - Motivos que levam a utilizar os caracteres humanos na contextualização

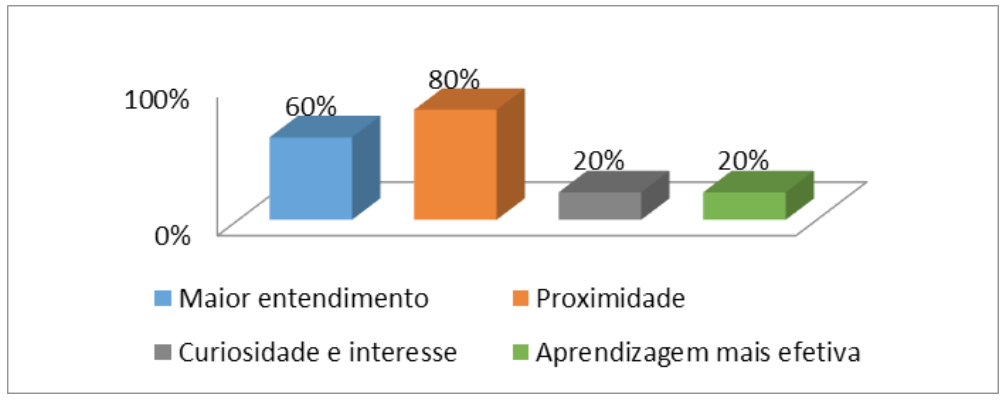

Fonte: Os autores.

Questionados sobre o fato de terem se deparado com situações inusitadas no ensino de Genética, percebe-se que 67\% dos professores já toparam com questionamentos fora do comum, constrangedores, ou para os quais não tinham resposta ou não sabiam como lidar com a situação. Quando indagados sobre o que fazem em relação a isso, cerca da metade desses citam buscar informações "corretas" sobre as questões em sites na Internet. Cabe destacar que, em razão da dificuldade de encontrar informações corretas, alguns relatam evitar comentar sobre assuntos polêmicos. Dos temas citados nessas ocasiões, o mais polêmico é a cor de olho (60\%), seguido dos grupos sanguíneos, demais doenças e casos específicos visualizados em colegas da classe, como a heterocromia.

Dos professores que citaram ter se deparado com situações inusitadas, $70 \%$ afirmaram que elas eram relacionadas a suspeitas com relação à paternidade, e, destes, $20 \%$ relataram casos de adoção, em que um deles levou os pais a reconhecerem a adoção; situação extremamente preocupante, considerando que da forma como estamos ensinando (herança poligênica tratada como herança monogênica) podem-se incitar inúmeras outras dúvidas desnecessárias entre os alunos e que nem sempre vão encontrar fundamentação científica. 
Quando solicitados que descrevessem alguns padrões de herança e exemplos utilizados, percebe-se, de forma muito clara, a distribuição dos caracteres humanos herdados nos padrões monogênicos de herança, em que $80 \%$ citam olhos claros e escuros como exemplo de gene dominante e recessivo, 33,3\% citam o cabelo crespo como dominante em relação aos cabelos lisos, e o mesmo percentual utiliza os cabelos escuros em relação aos cabelos claros. Demais exemplos empregados estão destacados na Figura 7, a seguir.

Figura 7 - Frequência de caracteres humanos herdados atribuídos à herança monogênica na percepção dos professores do Ensino Médio

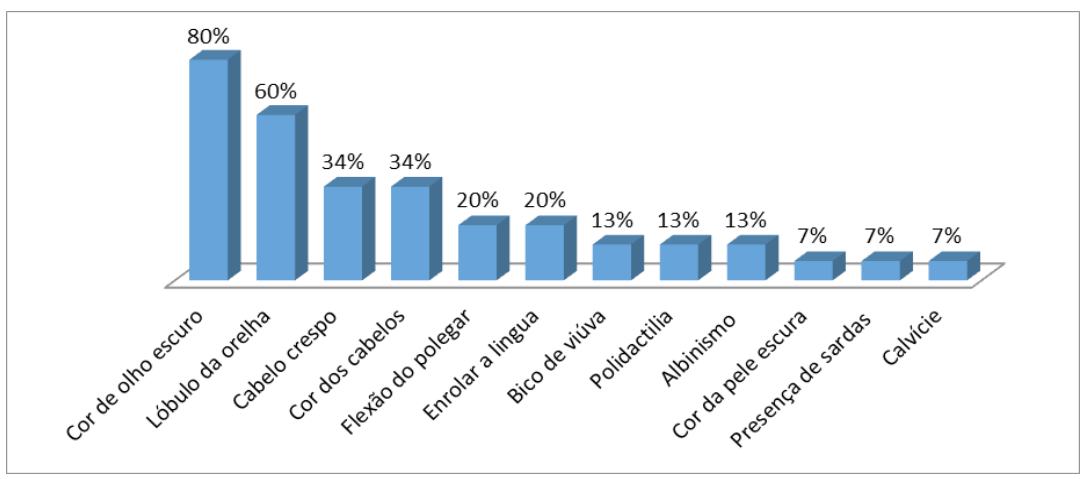

Fonte: Os autores.

A listagem dos exemplos utilizados pelos professores retrata os exemplos disponibilizados nos livros didáticos, como demonstram os resultados de uma avaliação específica com relação ao emprego de caracteres humanos na contextualização de padrões de herança monogênica em livros didáticos (PNLD/2012), identificando como mais comuns: o lóbulo da orelha, o albinismo, a fibrose cística, a fenilcetonúria, o daltonismo; seguidos de acondroplasia, de sensibilidade ao PTC, de polidactilia, da habilidade para destro ou canhoto, do gene para Alzheimer precoce, da galactosemia e da cor do olho, que se assemelham aos descritos pelos professores (BAIOTTO; SEPEL; LORETO, 2016).

Reflexões sobre quais exemplos usar para o ensino dos padrões de herança mendelianos, com destaque para suas vantagens e desvantagens, podem ser lidos em "Para ensinar genética mendeliana: ervilhas ou lóbulos de orelhas?", disponível na Revista Genética na Escola (BAIOTTO; SEPEL; LORETO, 2016). 
Nesse sentido, a utilização de caracteres humanos herdados como forma de contextualizar herança monogênica, mesmo que de forma simplificada, amplia consideravelmente os problemas associados à visão determinista da genética. Essa visão determinista e individualizada dos genes no desenvolvimento das características sem influência do ambiente é apontada por Shaw et al. (2008) e Ferreira, Silva e Carvalho (2009) como um dos principais equívocos entre os estudantes.

Herança complexa interpretada como monogênica ignora a participação de outros genes no funcionamento normal dos processos bioquímicos envolvidos no desenvolvimento dessa característica, como, por exemplo, os caminhos bioquímicos que levam à síntese dos pigmentos do olho (MEYER; BOMFIM; EL-HANI, 2013). A expressão mais presente entre os entrevistados, ao identificar quais caracteres utilizam com mais frequência nesse tópico de ensino, remete à "gene para", que ignora a influência epigenética e ambiental sobre esse caráter (por exemplo, "um gene para olhos azuis").

Moss (2003) afirma que o fator preditivo de um gene ("um gene para"), utilizado de forma simplificada, contribui na interpretação de heredogramas e na análise probabilística nos cruzamentos. Caracteres poligênicos, doenças complexas e multifatoriais, entretanto, quando tratados de forma monogênica, seja por simplificação, falta de informação, de atualização, ou com a finalidade de estimular o aluno a resolver "problemas de probabilidade", ampliam os equívocos e as inconsistências no ensino dos padrões de herança em genética, posto que esses traços podem ser facilmente observáveis em si mesmos e em seus familiares e, desse modo, descaracterizar a informação científica. Convém ressaltar que $20 \%$ dos professores (todos com menos tempo de formação) utilizam exemplos adequados e ao se referir à cor de pele, descrevem-na como um padrão de herança quantitativa.

Além do determinismo genético incutido nos extensos cálculos de probabilidade utilizando caracteres humanos herdados, outra dificuldade que resulta dessa forma de contextualizar padrões de herança monogênicos é a falsa ideia de homogeneidade genética. Compreender heterogeneidade genética necessita compreender mutações e efeitos moleculares associados, considerando que 
mutações diferentes no mesmo lócus ou em lócus diversos são responsáveis por fenótipos similares (SCHAEFER; THOMPSON, 2015). Do mesmo modo, muitos conceitos que envolvem mecanismos moleculares são passíveis de sofrer diferentes apropriações pelos estudantes porque envolvem a integração de diversos níveis de organização: "o molecular (genes), o micro (cromossomos) e o macro (características fenotípicas e padrões de herança)" (CAMARGO; INFANTE-MALACHIAS, 2007). Essa forma de abordagem da genética, integrada à biologia molecular, complica ainda mais as representações simbólicas e simplificadas de representar características humanas ("A" e "a") no ensino de Genética.

Saka et al. (2006) demonstraram que os futuros professores possuem entendimentos inadequados da relação entre alguns conceitos genéticos básicos, como os relativos à herança mendeliana e termos como mitose/meiose e cromossomos homólogos. Já Caldeira e Meglhioratti (2011) verificaram a existência de diferentes conceitos para gene entre professores universitários. Para Santos e Martins (2009), essa compreensão inadequada pode influenciar a aprendizagem de conteúdos genéticos mais complexos.

Percebe-se, a partir da análise das entrevistas realizadas, um ensino focado, principalmente, em herança mendeliana simples, analisado por meio do quadrado de Punnett. Knippels, Waarlo e Boersma (2005) complementam que o foco não deve estar em resolver cruzamentos genéticos tradicionais, mas, sim, em estabelecer relações entre conceitos importantes, como reprodução, meiose e características genéticas. Redfiel (2012) afirma que precisamos gastar menos tempo em cruzamentos genéticos simples, em que genes únicos causam resultados fenotípicos, e apresentar aos alunos caracteres complexos quantitativos.

Enfim, entre tantas considerações, cabe um destaque para Smith e Wood (2016), que ressaltam que a explosão de conhecimento de conteúdo genético vem progressivamente substituindo a Genética formal, essencialmente mendeliana, pela compreensão biológica mais dinâmica do material hereditário (fluxo de informações, trocas e armazenamento), com uma abordagem de ensino ativa, permeada por desafios e investigações que possam ser avaliados, possibilitando readequações sempre que necessário. 


\section{Considerações Finais}

Os caracteres humanos herdados são utilizados pela totalidade dos professores na contextualização dos padrões de herança em razão da facilidade de compreensão, por se aproximar do cotidiano e por estimular a curiosidade e o interesse, o que favorece a aprendizagem. Cor do olho e dos cabelos, lóbulo da orelha, textura dos cabelos, flexão do polegar e capacidade de enrolar a língua, estão entre os principais exemplos de caracteres humanos usados pelos professores na contextualização de herança monogênica, embora nem todos sejam abordados sob a forma correta de herança. Destaca-se a tendência a reduzir as características genéticas a um padrão monogênico de herança, que pode ser resolvido pelo quadro de Punnett.

Dificuldades relacionadas à utilização dos caracteres humanos, a situações inusitadas e questões polêmicas, são relatadas pelos professores, que preferem manter o uso desses exemplos e resolver as questões que surgem em sua decorrência. É necessário considerar que os desvios e equívocos encontrados com relação ao padrão de herança dos caracteres humanos, podem dificultar ou entrar em choque com o conhecimento científico, cultural e social discutido na sala de aula.

Embora com uma confiabilidade de apenas 53\% entre os professores, o livro didático é utilizado por todos os professores entrevistados no planejamento e adotado como livro-texto por $80 \%$. Para solucionar suas dúvidas, procuram informações em outros livros didáticos ou na Internet, e apenas $6 \%$ destacam a necessidade de buscar essas informações em revistas específicas da área. A disponibilidade dos livros a partir do ingresso das escolas no PNLD, o reduzido tempo do professor para a pesquisa e busca de materiais didáticos para a organização de suas aulas e o custo elevado dos livros disponíveis no mercado, praticamente tornam o professor refém da informação contida nesses materiais.

Entende-se como necessária a contextualização no ensino de Genética pela utilização dos caracteres humanos hereditários, no entanto sugere-se: maior cuidado dos autores ao empregar simplificações e generalizações; mais atenção dos professores ao fazer a transposição didática e a contextualização no ensino; 
a redução do uso do livro didático como única fonte de consulta e material de aula; e a utilização de metodologias diferenciadas de ensino, em que o aluno se torne o protagonista do seu processo de aprendizagem, investigando e avaliando traços hereditários humanos de herança monogênica reconhecida.

\section{Referências}

ALTUNOOLU, B. D.; SEKER, M. The Understandings of Genetics Concepts and Learning Approach of Pre-Service Science Teachers. Journal of Educational and Social Research, v. 5, n. 1, april 2015. DOI: 10.5901/jesr.2015.v5n1s1p61.

BAIOTTO, C. R.; SEPEL, L. M. N.; LORETO, É. L.S. Para ensinar genética mendeliana: ervilhas ou lóbulos de orelhas. Genética na Escola, v. 11, p. 286-293, 2016. Disponível em: <http://docs.wixstatic.com/ugd/b703be_2cdb152d15264daf9419bc8a9c60b654. pdf>. Acesso em: 20 ago. 2017.

BARDIN, L. Análise de conteúdo. São Paulo: Edições 70, 2011.

BEZERRA, R. G.; GOULART, L. S. Levantamento e análise de conceitos genéticos entre alunos do Ensino Médio de um colégio público do Estado de Goiás. Revista Eletrônica de Biologia (REB), v. 6, n. 3, p. 214-233, abr. 2014. Disponível em: <https://revistas. pucsp.br/index.php/reb/article/view/13334/14343>. Acesso em: 30 ago. 2017.

BRASIL. Ministério da Educação e Cultura. Guia do Programa Nacional do Livro Didático (PNLD). Brasília: MEC; SEF, 2008.

. Ministério da Educação e Cultura. Secretaria de Educação Básica. Parâmetros Curriculares Nacionais do Ensino Médio: Ciências da Natureza, Matemática e suas Tecnologias. Brasília: MEC; SEMTEC, 1999.

CALDEIRA, A. M. A.; MEGLHIORATTI, F. A. Conceitos de gene: construção histórico-epistemológica e percepções de professores do ensino superior. Investigações em Ensino de Ciências, v. 16, n. 2, p. 201-222, 2011. Disponível em: <https://repositorio.unesp.br/ handle/11449/134636>. Acesso em: 30 ago. 2017.

CAMARGO, S. S.; INFANTE-MALACHIAS, M. E. A genética humana no Ensino Médio: algumas propostas. Genética na Escola, v. 2, n. 1, p. 14-16, 2007. Disponível em: <http://docs.wixstatic.com/ugd/b703be_213a6a6514ba4157b7327c516b634d33. pdf >. Acesso em: 31 ago. 2017.

CARVALHO, G. S. A transposição didática e o ensino de biologia. In: CALDEIRA, A. M. A.; ARAUJO, E. S. N. N. (Org.). Introdução à didática da biologia. São Paulo: Escrituras Editora, 2010. 
CASTELÃO, T. B.; AMABIS, J. M. Motivação e ensino de genética: um enfoque atribucional sobre a escolha da área, prática docente e aprendizagem. In: CONGRESSO BRASILEIRO DE GENÉTICA, 54, 2008, Salvador. Anais... Salvador, 2008.

CHEVALLARD, Y. La Transposición Didáctica: del saber sabio al saber enseñado. Buenos Aires: Aique, 1997. Disponível em: <https://www.researchgate.net/publication/242760000_La_transposicion_didactica_Del_saber_sabio_al_saber_ensenado $>$. Acesso em: 21 ago. 2017.

CIMER, A. What makes biology learning difficult and effective: students' views. $E d u$ cational Research and Reviews, v. 7, n. 3, p. 61-71, 2012. DOI: 10.5897/ERR11.205.

CIRNE, A. D. P. P.; COSTA, I. A. S. Concepções alternativas sobre conceitos de genética no ensino fundamental. Metáfora Educacional, n. 19, p. 53-79, 2015. Disponível em: $<$ http://www.valdeci.bio.br/pdf/n19_2015/n19_2015_cirne_costa_concepcoes_alternativas.pdf>. Acesso em: 31 ago. 2017

EL-HANI, C. N.; ROQUE, N.; ROCHA, P. L. B. Livros didáticos de biologia no Ensino Médio: resultados do PNLEM/2007. Educação em Revista, v. 27, n. 1, p. 211-240, abr. 2011. DOI: http://dx.doi.org/10.1590/S0102-46982011000100010.

FERREIRA, C.; SILVA, C.; CARVALHO, G. S. Doenças genéticas e determinismo genético em manuais escolares: comparação entre Portugal e França. In: SEMINÁRIO INTERNACIONAL, V/IBERO-AMERICANO DE EDUCAÇÃO FÍSICA, LAZER E SAÚDE, 2., São Miguel, 2009. Actas... São Miguel, Açores, 2009.

FRANZOLIN, F.; BIZZO, N. Types of Deviation in Genetics Knowledge Presented in Textbooks Relative to the Reference Literature. Procedia - Social and Behavioral Sciences, v. 167, 2015, p. 223-228. DOI: https://doi.org/10.1016/j.sbspro.2014.12.666.

FRANZOLIN, F.; TOLENTINO-NETO, L. C. B.; BIZZO, N. Generalizações que distanciam os conhecimentos dos livros didáticos das referências em Genética. Investigações no Ensino de Genética. Genética na Escola, v. 9, n. 2, 2014. Disponível em: <https://www. researchgate.net/profile/Luiz_Tolentino-Neto/publication/268216054_Generalizacoes_ que_distanciam_os_conhecimentos_dos_livros_didaticos_das_referencias_em_Genetica/ links/5464fefc0cf25b85d17d23b9/Generalizacoes-que-distanciam-os-conhecimentos-dos-livros-didaticos-das-referencias-em-Genetica.pdf>. Acesso em: 21 ago. 2017.

GARCIA, P. S.; BIZZO, N. A pesquisa em livros didáticos de ciências e as inovações no ensino. Educação em Foco, v. 15, p. 13-35, 2010. Disponível em: <http://revista. uemg.br/index.php/educacaoemfoco/article/viewFile/89/124>. Acesso em: 21 ago. 2017.

GASKELL, G. Entrevistas individuais e grupais. In: BAUER, M. W.; GASKELL, G. (Org.). Pesquisa qualitativa com texto, imagem e som: um manual prático. Petrópolis: Vozes, 2002. p. 64-89. 
GERICKE, N. Science versus School-science; multiple models in genetics - the depiction of gene function in upper secondary textbooks and its influence on students' understanding. 2009. Tese (Doutorado em Biology Education) - Universidade de Karlstad, Karlstad, 2009.

GIACÓIA, L. R. D. Conhecimento básico de genética: concluintes do Ensino Médio e graduandos de Ciências Biológicas. 2006. Dissertação (Mestrado em Educação para a Ciência) - Universidade Estadual Paulista, Bauru, 2006.

GIL, A. C. Como elaborar projetos de pesquisa. 4. ed. São Paulo: Atlas, 2002.

INFANTE-MALACHIAS, M. E. et al. Comprehension of basic genetic concepts by Brazilian undergraduate students. Revista Electrónica de Enseñanza de las Ciencias, v. 9, n. 3, p. 657-668, 2010. Disponível em: <http://reec.uvigo.es/volumenes/volumen9/ ART9_Vol9_N3.pdf>. Acesso em: 21 ago. 2017.

KATO, D. S.; KAWASAKI, C. S. As concepções de contextualização do ensino em documentos curriculares oficiais e de professores de ciências. Ciência \& Educação, v. 17, n. 1, p. 35-50, 2011. DOI: http://dx.doi.org/10.1590/S1516-73132011000100003.

KNIPPELS, M. C. P. J.; WAARLO, A. J.; BOERSMA, K. Design Criteria for Learning and Teaching Genetics. Journal of Biological Education, v. 39, n. 3, p. 108-112, 2005. DOI: http://dx.doi.org/10.1080/00219266.2005.9655976.

LIMA, J. F. L. et al. A contextualização no ensino de cinética química. Química Nova na Escola, n. 11, p. 27-29, 2000. Disponível em: <http://qnesc.sbq.org.br/online/qnesc11/ v11a06.pdf>. Acesso em: 18 ago. 2017.

LORETO, É. L. S.; SEPEL, L. M. N. A escola na era do DNA e da Genética. Ciência e Ambiente, v. 26, p. 149-156, 2003.

MAIA, J. O.; VILANI, A. A relação de professores de Química com o livro didático e o caderno do professor. Revista Electrónica de Enseñanza de las Ciencias, v. 15, n. 1, p. 121-146, 2016. Disponível em: <http://reec.uvigo.es/volumenes/volumen15/ REEC_15_1_7_ex969.pdf>. Acesso em: 28 ago. 2017.

MALAFAIA, G.; BÁRBARA, V. F.; RODRIGUES, A. S. Análise das concepções e opiniões de discentes sobre o ensino da biologia. Revista Eletrônica de Educação, v. 4, n. 2, p. 165-182, 2010. DOI: http://dx.doi.org/10.14244/1982719994.

MEYER, L.; BOMFIM, G.; El-HANI, C. How to Understand the Gene in the TwentyFirst Century? Science \& Education, v. 22, n. 2, p. 345-374, 2013. DOI: https://doi. org/10.1007/s11191-011-9390-z.

MOSS, L. What Genes Can't Do. Cambridge, MA: MIT Press, 2003. Disponível em: $<$ http://www.enu.kz/repository/repository2014/what-genes.pdf>. Acesso em: 28 ago. 2017. 
MOURA, J. et al. Biologia/genética: o ensino de biologia, com enfoque a genética, das escolas públicas no Brasil - breve relato e reflexão. Semina: Ciências Biológicas e da Saúde, v. 34, n. 2, p. 167-174, jul./dez. 2013. DOI: http://dx.doi.org/10.5433/1679$-0367.2013 v 34 n 2 p 167$

NOVAK, J. D. Uma teoria de educação: aprendizagem significativa subjacente à integração construtiva de pensamentos, sentimentos e ações levando ao empoderamento para compromisso e responsabilidade. Aprendizagem Significativa em Revista/Meaningful Learning Review, v. 1, n. 2, p. 1-14, 2011. Disponível em: <http://www.if.ufrgs.br/asr/ artigos/Artigo_ID7/v1_n2_a2011.pdf>. Acesso em: 28 ago. 2017.

PAIVA, A. L. B.; MARTINS, C. M. C. Concepções prévias de alunos de terceiro ano do Ensino Médio a respeito de temas na área de Genética. Ensaio Pesquisa em Educação em Ciências, v. 7, n. 3, p. 182-201, 2005. DOI: http://dx.doi.org/10.1590/198321172005070303.

PIMENTA, S. G.; GONÇALVES, C. L. Revendo o ensino do $2^{o}$ grau, propondo a formação de professores. 2. ed. São Paulo: Cortez, 1992.

REDFIELD, R. J. "Why do we have to learn this stuff?"-A new genetics for 21 st century students. PLoS Biology, n. 10, 2012. DOI: 10.1371/journal.pbio.1001356.

RICHARDSON, R. J. Pesquisa social: métodos e técnicas. São Paulo: Atlas, 1999.

SAKA, A. et al. A cross-age study of the understanding of three genetic concepts: How do they image the gene, DNA and chromosome? Journal of Science Education and Technology, v. 15, n. 2, p. 192-202, 2006. DOI: https://doi.org/10.1007/s10956-006-9006-6.

SANTOS, E.; MARTINS, I. P. Ensinar sobre alimentos geneticamente modificados. Contribuições para uma cidadania responsável. Revista Eletrônica de Esnseñanza de las Ciencias, v. 8, n. 3, p. 834-858, 2009. Disponível em: <http://reec.uvigo.es/volumenes/ volumen8/ART5_Vol8_N3.pdf>. Acesso em: 26 jul. 2017.

SANTOS, V. C.; EL-HANI, C. N. Ideias sobre genes em livros didáticos de biologia do ensino médio publicados no Brasil. Revista Brasileira de Pesquisa em Educação em Ciências, v. 9, n. 1, 2009. Disponível em: <https://seer.ufmg.br/index.php/rbpec/article/ view/2209/1608>. Acesso em: 28 jul. 2017.

SANTOS, W. L. P. Contextualização no ensino de Ciências por meio de temas CTS em uma perspectiva crítica. Ciência \& Ensino, v. 1, 2007. Disponível em: <http:// www.academia.edu/27297895/Contextualiza\%C3\%A7\%C3\%A3o_no_ensino_de_ ci\%C3\%AAncias_por_meio_de_temas_CTS_em_uma_perspectiva_cr\%C3\%ADtica>. Acesso em: 28 ago. 2017.

SCHAEFER, G. B.; THOMPSON, J. N. Genética médica: uma abordagem integrada. Tradução A. E. Vargas. Porto Alegre: AMGH, 2015. 
SCHEID, N. M. J.; FERRARI, N. A história da ciência como aliada no ensino de genética. Genética na Escola, v. 1, n. 1, p. 17-18, 2006. Disponível em: <http://docs.wixstatic. com/ugd/b703be_6418c0f6af7d445bbd186c47852833e5.pdf>. Acesso em: 26 jul. 2017.

SHAW, K. R. M. et al. Essay contest reveals misconceptions of high school students in genetics content. Genetics, v. 178, p. 1.157-1.168, 2008. DOI: 10.1534/genetics.107.084194.

SILVA, E.; MARCONDES, M. E. R. Visões de contextualização de professores de química na elaboração de seus próprios materiais didáticos. Revista Ensaio, v. 12, n. 1, p. 101-118, 2010. Disponível em: <http://www.scielo.br/pdf/epec/v12n1/1983-2117epec-12-01-00101.pdf>. Acesso em: 26 jul. 2017.

SMITH, M. K.; KNIGTH, J. K. Using the genetics concept assessment to document persistent conceptual difficulties in undergraduate genetics courses. Genetics, v. 191, n. 1, p. 21-32, 2012. DOI: 10.1534/genetics.111.137810.

SMITH, M. K.; WOOD, W. B. Teaching Genetics: Past, Present, and Future. Genetics, v. 204, n. 1, p. 5-10, 2016. DOI: 10.1534/genetics.116.187138.

TOLEDO, E. J. L.; FERREIRA, L. H. Transposição didática como reforço de obstáculos epistemológicos em livro texto e em experimentos didáticos. Revista Electrónica de Enseñanza de las Ciencias, v. 14, n. 2, 2015. Disponível em: <http://reec.uvigo.es/ volumenes/volumen14/REEC_14_2_6_ex964.pdf>. Acesso em: 26 jul. 2017.

TSUI, C. Y.; TREAGUS, D. F. Understanding genetics: analysis of secondary students' conceptual status. Journal of Research in Science Teaching, v. 44, n. 2, p. 205-235, 2007. DOI: $10.1002 /$ tea.20116. 